\title{
The Heterogeneous Reverse Osmosis Membranes Based Separation of Fluorides with Fly Ash Pretreatment
}

\author{
B.S. ThaÇI AND S.T. GASHI* \\ Department of Chemistry, Faculty of Natural Sciences, University of Prishtina, 10000 Prishtinë, Republic of Kosova
}

\begin{abstract}
The objective of this paper was to examine the separation efficiency of fluorides by heterogeneous reverse osmosis membranes made from cellulose acetate and modified coal with aryl diazonium salt (batch $318 \mathrm{~K}$ ) and lignite based fly ash pretreatment. The effect of varying the feed concentration $\left(400-100 \mathrm{mg} / \mathrm{dm}^{3}\right)$ of sodium and ammonium fluorides on performances of these membranes using $400 \mathrm{mg} / \mathrm{dm}^{3}$ aqueous solution of sodium chloride as referent system at 1.76 MPa have been investigated. Practically no significant change in the membrane characteristics (product rate, and solute separation) by varying the above concentration of feed salt solutions. The high separation of fluoride (synthetic sample) $\approx 99 \%$ was obtained by resulting membranes pretreated with different amount and contact time of low cost adsorbent (fly ash) at $\mathrm{pH} 4$. A sample of waste water effluents of cement industry was also treated with above membranes without pretreatment and the results are presented. These data indicate that the fluoride ion concentration are within acceptable level as far as environmental limits concerned, therefore, their practical application produced water of suitable quality, essentially free from fluorides.
\end{abstract}

DOI: 10.12693/APhysPolA.128.B-62

PACS: 82.45.Mp, 89.30.ag, 89.60.-k

\section{Introduction}

Two sources of fluoride pollution and fluoride toxicity to plants, animals, and man come from natural sources such a volcanic gases and soluble fluorides in the earth's crust, as well as large quantities of fluorides discharged into streams, rivers, lakes and oceans as a component of industrial waste waters.

The soluble fluoride emissions from the steel industry, coal combustion, phosphate fertilizer and elemental phosphorous plants, primary aluminum production, heavy clay products, glass manufacture, frit smelting, cement manufacture, nonferrous metals ( $\mathrm{Zn}, \mathrm{Cu}, \mathrm{Pb}$, etc.) and nanotechnology industries such as glass and silica etchant, hydrofluoric acid products and alcylation process, are major sources of fluoride waste water effluents.

Numerous physical or chemical treatment methods e.g. precipitation [1-3], adsorption [4-6], ion exchange [7], or electrochemical methods [8-10], etc. have been applied to remove fluorides from waste water effluents.

In the last decades, on many occasions, the membrane processes look more and more promising as separation processes in industry and water purification.

Reduction of fluorine by electrodialysis from a brackish water containing $3000 \mathrm{mg} / \mathrm{dm}^{3}$ of total dissolved solids (TDS) and $3 \mathrm{mg} / \mathrm{dm}^{3}$ of fluoride without pretreatment demonstrated that electrodialysis is a reasonable process for removal fluoride from brackish water [11].

The heterogeneous reverse osmosis (RO) membranes made from cellulose acetate and modified coal with aryl diazonium salt showed high separation performance, low cost and seem promising for the treatment of waste water effluents and at low operating pressure [12].

*corresponding author; e-mail: salihtg@yahoo.com
The ammonium fluoride solutions and uranium fluoride effluents (UFE) have been treated with a continuous feedback $\mathrm{RO}$ process. The solute rejections of $\mathrm{NH}_{4}^{+}, \mathrm{F}^{-}$, and $\mathrm{U}^{6+}$ depend heavily on the feed $\mathrm{pH}$ value. Accordingly, the fluoride ions can be separated from UFE under acidic conditions [13].

The rejection of fluoride ions from electronic industrial effluents is typically higher than $98 \%$ considering that the $\mathrm{RO}$ membrane was fully regenerated after each set of experiments. The process developed in this study has demonstrated that $\mathrm{RO}$ can be considered for retention of fluorides, even for high concentration. This application is really a novelty and a technological progress for the treatment of electronic effluents [14].

RO has achieved significant removal of fluorides and virtually all dissolved contaminants. With the improvements in membrane quality and module design, $\mathrm{RO}$ has been developed as one of the most important membrane processes in industrial applications [15].

The methods of separation of fluorides differ in their efficiency cost and environmental impact. Persistent efforts have recently been made to build up highly effective, low cost and available methods for removal of fluorides. High level of fluorides are generally reduced by precipitation of $\mathrm{CaF}_{2}$ with lime. However the solubility of $\mathrm{CaF}_{2}$ is such that residual fluoride in industrial waters could be considerably higher. Since pollution standards require lower remaining fluorides, in many cases the clear filtrating after fly ash treatment looked the best way for reduction of fluorides to acceptable level and thus was used as feed for RO treatment. The goal of this work was the performance of cellulose acetate coal heterogeneous RO membranes in separation of fluoride salt solutions, synthetic sample of high different concentrations of fluorides with optimized fly ash pretreatment. 


\section{Materials and methods}

Cellulose acetate Eastman Kodak 398-3 with degree of acetylation $39.85 \%$ and Kosova's (Bardh i Madh), modified coal with aryl diazonium salt were used for preparation of heterogeneous asymmetric RO membranes.

\subsection{Coal modification}

Coal modification in aqueous solution was as follows: the coal specimens were treated with boiling water under stirring conditions. The residual coal after filtering was dried at $105^{\circ} \mathrm{C}$ to constant weight. Typically $8 \mathrm{~g}$ of this coal was dispersed in $100 \mathrm{~cm}^{3}$ phosphoric acid containing $20 \mathrm{mM}$ of $\mathrm{N}_{2} \mathrm{C}_{6} \mathrm{H}_{4} \mathrm{BF}_{4}$. The solution was stirred at temperature $5{ }^{\circ} \mathrm{C}$ controlled water bath for $5 \mathrm{~h}$. The reaction mixture was filtered with a 589 Blue ribbon and then the modified coal was washed by successive aliquots of water. Finally the modified coal was dried at $105^{\circ} \mathrm{C}$ to the constant weight, ground and sieved. The coal fractions of sieve size of $\approx 170$ mesh were used in this study.

\subsection{Film casting details and RO procedure}

The film casting details for the investigated membranes are casting solution composition cellulose acetate (E 398-3) 10 wt\%, modified coal with aryl diazonium salt $15 \mathrm{wt} \%$, with corresponding amounts of acetone $61.3 \mathrm{wt} \%$, water $12.25 \mathrm{wt} \%$, and magnesium perchlorate $1.45 \mathrm{wt} \%$ at temperature of casting solution and casting atmosphere $24^{\circ} \mathrm{C}$ and ambient air (relative humidity $60 \%$ ). The membranes made with modified coal in a medium of phosphoric acid were named $318 \mathrm{~K}-1$ (the letter $\mathrm{K}$ means Kosova's coal and 1 means above weight ratios CA-coal). The films were cast on a clean glass plate $\left(22 \times 38 \mathrm{~cm}^{2}\right)$ with the use of a metal cylinder with uplifted edges to obtain the required film thickness $(0.12 \mathrm{~mm})$. The glass plate was kept at the same temperature as the casting solution. The casting solution temperature and the external conditions of solvent evaporation time $(0 \mathrm{~s})$ during film casting were the same for all series of films studied. The cast solution was immediately dipped into a gelation bath consisting ice cold water $\left(0^{\circ} \mathrm{C}\right)$. The duration of the film setting in ice cold water was $1 \mathrm{~h}$. Before the RO experiment, the membranes were preshrunk under water at different temperatures (the temperature of water bath was controlled to within $\pm 0.5^{\circ} \mathrm{C}$ ) and initially each film was subjected to pure water pressure treatment for $1 \mathrm{~h}$ at $20 \%$ higher pressure than that to be used in RO run.

The membranes, five samples of each type, were tested in the same RO apparatus [16]. The surface area of the membranes investigated was $11.92 \mathrm{~cm}^{2}$. All RO experiments with sodium chloride solutions as a reference system were of the short-run-type lasting for about $3 \mathrm{~h}$, and performed at laboratory temperature and pressure of $1.76 \mathrm{MPa}$. The membrane performance data were obtained for conditions of feed concentration and feed flow rate corresponding to a mass transfer coefficient $k$ of $45 \times 10^{-4} \mathrm{~cm} / \mathrm{s}$ on the high pressure side of membrane, using aqueous sodium chloride feed solution of $400 \mathrm{mg} / \mathrm{dm}^{3}$. Mass transfer coefficient $k$ was kept constant in all experiments. The concentration of sodium chloride and the other single salts: sodium fluoride, ammonium fluoride in the feed and the product solution were determined by specific resistance measurements. At the end of each series of testing, the membranes were again tested with the same sodium standard solution.

Permeate flow rate, referring to the membranepermeated solution corrected to $25^{\circ} \mathrm{C}$, and the rejection factor $R$, defined as:

$$
R=1-\frac{C_{\mathrm{p}}}{C_{\mathrm{f}}} .
$$

$C_{\mathrm{p}}$ and $C_{\mathrm{f}}$ are permeate and feed concentrations $\left[\mathrm{g} / \mathrm{dm}^{3}\right]$.

\subsection{The fly ash pretreatment of synthetic sample of fluorides}

The lignite-based fly ash obtained from Kosova's thermal power plants was used as pretreatment step for RO . The fly ash was passed through a stack of sieves of size fractions of $\times 120$ mesh. Chemical analysis of the used fly ash is presented in Table I.

TABLE I

Chemical analysis of the fly ash.

\begin{tabular}{c|c}
\hline \hline Constituents & $\begin{array}{c}\text { Fly ash } \\
\text { [wt\%] }\end{array}$ \\
\hline loss on ignition & 2.20 \\
$\mathrm{SiO}_{2}$ & 26.75 \\
$\mathrm{Al}_{2} \mathrm{O}_{3}$ & 4.00 \\
$\mathrm{Fe}_{2} \mathrm{O}_{3}$ & 10.77 \\
$\mathrm{CaO}$ & 41.48 \\
$\mathrm{MgO}$ & 4.36 \\
$\mathrm{Na}_{2} \mathrm{O}$ & 1.42 \\
$\mathrm{~K}_{2} \mathrm{O}$ & 0.16 \\
$\mathrm{TiO}_{2}$ & 0.50
\end{tabular}

The polyethylene bottles with hydrofluoric acid solution of fluoride concentration in the feed $\left(400 \mathrm{mg} / \mathrm{dm}^{3}\right)$ and different amounts of fly ash were placed for half an hour in a temperature controlled water bath under stirring at $25^{\circ} \mathrm{C}$. Then the same fluoride concentration was treated with fly ash $\left(2 \mathrm{~g} / \mathrm{dm}^{3}\right)$ at different contact time. The supernatant was filtered with a 589 Blue ribbon and residual concentration was determined in clear filtrate by spectrophotometer DR/4000 UV-VIS HACH at wave length $580 \mathrm{~nm}$. The $\mathrm{pH}$ of the solution was 4 . A sample of cement industry waste water effluents was filtered with 589 Blue Ribbon and used as feed for further treatment by membranes. The $\mathrm{pH}$ adjustment of synthetic sample after treatment with fly ash was done with a few drops of $1 \mathrm{M} \mathrm{NaOH}$.

Both fluoride feed solutions were subjected to RO experiments under conditions as in permeable test at $\mathrm{pH} 6$ and 6.2 , respectively. 


\section{Results and discussion}

The performance data obtained by heterogeneous cellulose acetate-coal RO membranes (batch 318K-1) are given in Table II. These membranes were specified in terms of pure water permeability constant $A$, gmol $\mathrm{H}_{2} \mathrm{O} /\left(\mathrm{cm}^{2} \mathrm{~Pa}\right)$, and solute transport parameter, $D_{A M} / K \delta[\mathrm{cm} / \mathrm{s}]$, at the operating pressure used in the experiment for aqueous sodium chloride solution (of concentration $400 \mathrm{mg} / \mathrm{dm}^{3}$ ) as reference system for five tested films.

Further experiments were performed to evaluate RO performance of used membranes in separation of fluorides.

TABLE II

The performance data of CA-modified coal membranes (batch $318 \mathrm{~K}-1$ ) at $1.76 \mathrm{MPa}$.

\begin{tabular}{c|c|c|c|c|c|c}
\hline \hline $\begin{array}{c}\text { film } \\
\text { no. }\end{array}$ & $\begin{array}{c}\text { shrinkage } \\
\text { temperature } \\
{ }^{\circ} \mathrm{C}\end{array}$ & $\begin{array}{c}A \times 10^{-11} \\
{\left[\mathrm{~g} \mathrm{~mol} \mathrm{H}_{2} \mathrm{O} /\right.} \\
\left.\left(\mathrm{cm}^{2} \mathrm{~s} \mathrm{~Pa}\right)\right]\end{array}$ & $\begin{array}{c}D_{A M} / K \delta \\
{\left[\mathrm{cm} / \mathrm{s} \times 10^{-4}\right]}\end{array}$ & $\begin{array}{c}\text { sep. } f \\
{[\%]}\end{array}$ & $\begin{array}{c}\text { product } \\
\text { rate }(\mathrm{PR}) \\
{[\mathrm{g} / \mathrm{h}]}\end{array}$ & $\begin{array}{c}\text { product water } \\
\text { rate }(\mathrm{PWR}) \\
{[\mathrm{g} / \mathrm{h}]}\end{array}$ \\
\hline 1 & 88 & 2.18 & 0.34 & 95.01 & 33.04 & 33.71 \\
2 & 85 & 2.40 & 0.55 & 92.58 & 35.74 & 37.11 \\
3 & 82 & 3.89 & 1.50 & 87.03 & 58.59 & 60.19 \\
4 & 82 & 5.32 & 4.97 & 71.23 & 79.98 & 82.32 \\
5 & 80 & 6.87 & 7.40 & 65.13 & 97.91 & 106.2 \\
\hline
\end{tabular}

Solution system: $\mathrm{NaCl}-\mathrm{H}_{2} \mathrm{O}$, feed concentration: $400 \mathrm{mg} / \mathrm{dm}^{3}$, membrane area: $11.92 \mathrm{~cm}^{2}, k=45 \times 10^{-4} \mathrm{~cm} / \mathrm{s}$.

TABLE III

The data of solute separations and product rate of sodium and ammonium fluorides with membranes (batch 318K-1) at $1.76 \mathrm{MPa}$.

\begin{tabular}{c|c|c|c|c|c|c|c|c|c|c|c}
\hline \multicolumn{2}{c|}{ Salts } & \multicolumn{2}{c|}{ Film 1 } & \multicolumn{2}{c|}{ Film 2 } & \multicolumn{2}{c|}{ Film 3 } & \multicolumn{2}{c}{ Film 4 } & \multicolumn{2}{c}{ Film 5 } \\
\hline \multicolumn{2}{c|}{$[\mathrm{ppm}]$} & $f[\%]$ & $\mathrm{PR}[\mathrm{g} / \mathrm{h}]$ & $f[\%]$ & $\mathrm{PR}[\mathrm{g} / \mathrm{h}]$ & $f[\%]$ & $\mathrm{PR}[\mathrm{g} / \mathrm{h}]$ & $f[\%]$ & $\mathrm{PR}[\mathrm{g} / \mathrm{h}]$ & $f[\%]$ & $\mathrm{PR}[\mathrm{g} / \mathrm{h}]$ \\
\hline $\mathrm{NaF}$ & $(100)$ & 95.12 & 36.78 & 92.07 & 37.10 & 87.54 & 60.43 & 71.82 & 75.11 & 66.87 & 95.52 \\
$\mathrm{NaF}$ & $(200)$ & 95.16 & 36.75 & 92.88 & 37.68 & 88.43 & 57.29 & 72.68 & 76.72 & 67.43 & 96.08 \\
$\mathrm{NaF}$ & $(400)$ & 95.10 & 36.30 & 93.58 & 35.74 & 89.03 & 58.59 & 73.03 & 78.67 & 67.98 & 96.97 \\
$\mathrm{NH}_{4} \mathrm{~F}$ & $(100)$ & 95.31 & 37.93 & 92.18 & 38.57 & 88.69 & 59.64 & 72.09 & 76.61 & 68.01 \\
$\mathrm{NH}_{4} \mathrm{~F}$ & $(200)$ & 96.03 & 37.34 & 92.09 & 38.53 & 88.97 & 59.45 & 72.44 & 75.04 & 68.22 & 94.53 \\
$\mathrm{NH}_{4} \mathrm{~F}$ & $(400)$ & 97.08 & 36.88 & 93.88 & 39.28 & 89.54 & 60.83 & 72.51 & 76.99 & 68.18 & 95.53
\end{tabular}

The experimental data on the product rate and percent solute separation for different feed concentrations of sodium and ammonium fluoride are presented in Table III.

The effect of the concentration variation in feed solutions of $\mathrm{NH}_{4} \mathrm{~F}-\mathrm{H}_{2} \mathrm{O}$ and $\mathrm{NaF}-\mathrm{H}_{2} \mathrm{O}$ on solute separation arbitrary chosen is shown in Fig. 1.

The percent solute separation obtained as a function of the feed concentration is depicted in Fig. 1. It is clear from Fig. 1 that the solute separation was increased smoothly in going from small to high concentrations of above salt solution. This trend holds through all films used in the present study. The same effect was obtained with product rate as a function of the feed concentration, respectively, the product rate was found to be constant with increase of resulting concentrations of fluorides.

Reference to Table III shows that solute separation 95$97 \%$, of sodium, respectively ammonium fluorides, was obtained under the experimental conditions used in the present work respectively, film three is the best from the point of view of maximum product rate at a high degree of solute separation. The separation order $\beta$ of studied salt solutions is as following: $\beta\left(\mathrm{NH}_{4} \mathrm{~F}\right)>\beta(\mathrm{NaF})>$ $\beta(\mathrm{NaCl})$, which corresponds with theoretical predictions.

The product rate corresponding to above degree of solute separation was $3.08 \times 10^{-2} \mathrm{~m}^{3} /\left(\mathrm{m}^{2} \mathrm{~h}\right)$, respectively $3.09 \times 10^{-2} \mathrm{~m}^{3} /\left(\mathrm{m}^{2} \mathrm{~h}\right)$, favorable for productive membranes. A synthetic sample of fluorides pretreated with fly ash was subjected to RO treatment under same conditions as in the permeability test. The chemical analysis of fly ash used in this work is presented in Table I. From the data it can be seen that main component of fly ash is calcium oxide which characterizes alkaline ashes, i.e. ashes which raise the $\mathrm{pH}$ of the solution.

The results of treatment of fluorides by fly ash are presented in Table IV. 


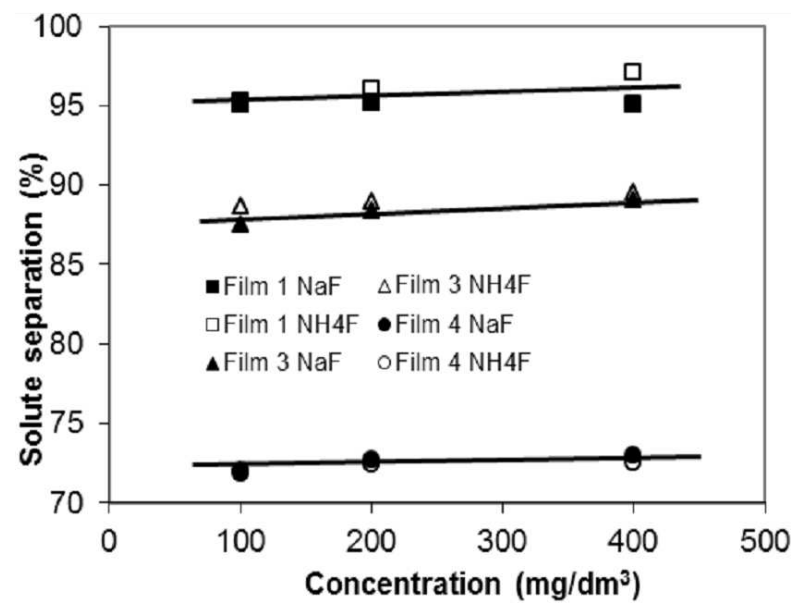

Fig. 1. Effect of sodium and ammonium fluoride ion concentration on solute separation.

TABLE IV

The synthetic sample of fluorides pretreated by fly ash, and RO membranes (batch $318 \mathrm{~K}-1$ ).

\begin{tabular}{|c|c|c|c|c|c|c|}
\hline 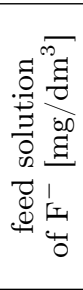 & 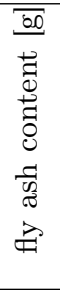 & 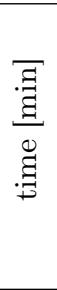 & 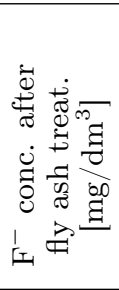 & 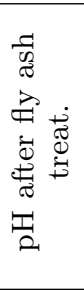 & 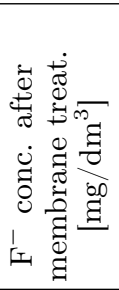 & 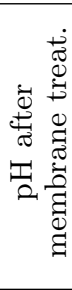 \\
\hline \multirow{3}{*}{440} & 2.5 & 30 & 265 & 4.32 & 10.25 & 6 \\
\hline & 5 & 30 & 165 & 4.31 & 7.9 & 6 \\
\hline & 10 & 30 & 75 & 4.38 & 5.8 & 6 \\
\hline \multirow{3}{*}{388} & 2 & 60 & 118 & 4.33 & 5.64 & 6 \\
\hline & 2 & 300 & 58 & 4.38 & 2.85 & 6 \\
\hline & 2 & 600 & 57 & 4.31 & 2.84 & 6 \\
\hline
\end{tabular}

From Table IV it is seen that with increase of the amount of fly ash at the same contact time (30 min) the fluoride content in remaining solution was decreased as a result of precipitation/adsorption of fluorides as calcium fluoride at $\mathrm{pH} 4.32-4.38$. For the same amount of fly ash $\left(2 \mathrm{~g} / \mathrm{dm}^{3}\right)$ at different contact time the content of fluorides was decrease to the half and then remained constant. The contact time of $5 \mathrm{~h}$ for achieving the fluoride concentration to be used as feed for $\mathrm{RO}$ treatment has been optimal. The content of fluorides in remaining solutions was treated by $\mathrm{RO}$ at $\mathrm{pH} 6$. At the end of each experiment, deviation in the final $\mathrm{pH}$ from desired values was acceptable. The above presented results show respective reduction of fluorides for further treatment with heterogeneous RO membranes.

The heterogeneous RO membranes were tested also with a sample of cement industry waste water effluents without pretreatment at $\mathrm{pH} 6.2$.

The results of fluorides and other components of cement industry waste water effluents subjected by membranes (batch 318K-1) without pretreatment are pre- sented in Table V.

TABLE V

The data of treated sample by membranes (batch $318 \mathrm{~K}-1)$ of cement industry waste water effluents.

\begin{tabular}{c|c|c}
\hline \hline Components & $\begin{array}{c}\text { feed water, } \\
\text { before RO treat. } \\
{\left[\mathrm{mg} / \mathrm{dm}^{3}\right]}\end{array}$ & $\begin{array}{c}\text { retentat } \\
{\left[\mathrm{mg} / \mathrm{dm}^{3}\right]}\end{array}$ \\
\hline $\mathrm{TDS}$ & 330 & $\leq 0.1$ \\
$\mathrm{Ca}^{2+}$ & 100.1 & 10.01 \\
$\mathrm{Mg}^{2+}$ & 15.19 & 3.04 \\
$\mathrm{NO}_{3}^{-}$ & 14.5 & 3.1 \\
$\mathrm{SO}_{4}^{2-}$ & 193 & $\leq 0.01$ \\
$\mathrm{Cl}^{-}$ & 24.8 & 0.51 \\
$\mathrm{~F}^{-}$ & 76 & 4 \\
$\mathrm{pH}$ & 6.8 & 6.2
\end{tabular}

The data from Table $\mathrm{V}$ indicates that resulting membranes (batch 318K-1) are readily available and effective for treatment of waste waters containing fluorides. Finally the achieved data show that concentration of fluorides was within high standards of fluoride waste waters [17].

\section{Conclusions}

The heterogeneous RO membrane characteristics were not significantly changed by varying feed concentration of fluoride salt solutions at low operating pressure. The high recovery of fluorides $(\approx 99 \%)$ was achieved by these membranes with optimized fly ash pretreatment. The pretreatment of fluoride solutions of high concentration (synthetic sample), with different amount of fly ash and different contact time at $\mathrm{pH} 4$, show satisfactory results in reduction of fluorides. The remaining fluorides in clear filtrate could be used properly as a feed for further treatment by $\mathrm{RO}$ membranes. The process developed with heterogeneous cellulose acetate coal RO membranes (batch 318K-1) and low cost adsorbent (fly ash) can be considered as a good prospect for the treatment of waste water effluents containing fluorides.

\section{References}

[1] M. Yang, T. Hashimoto, N. Hoshi, H. Myoga, Water Res. 33, 3395 (1999).

[2] J.C. Huang, J.C. Liu, Water Res. 33, 3403 (1999).

[3] B. Grzmil, J. Wronkowski, Desalination 189, 261 (2006).

[4] P.M.H. Kau, D.W. Smith, P. Binning, Geoderma 84, 89 (1998).

[5] N. Hamdi, E. Srasra, Desalination 206, 238 (2007).

[6] E. Diamadopoulos, S. Joannidis, G.P. Sakellaropoulos, Water Res. 27, 1773 (1993).

[7] C.M. Castel, O. Simonnot, M. Sardin, Chem. Eng. Sci. 55, 3341 (2000). 
[8] V.A. Joshi, M.V. Nanoti, Ann. Chim. 93, 753 (2003).

[9] C.Y. Hu, S.L. Lo, W.H. Kuan, Y.D. Lee, Water Res. 39, 895 (2005).

[10] C.Y. Hu, S.L. Lo, W.H. Kuan, Y.D. Lee, Separat. Purific. Technol. 60, 1 (2008).

[11] Z. Amor, B. Bernard, N. Mameri, M. Taky, S. Nocolas, A. Elmidaoui, Desalination 133, 215 (2001).

[12] S.T. Gashi, N.M. Daci, F.I. Podvorica, T. Selimi, B.S. Thaçi, Desalination 240, 1 (2009).

[13] Y. Chen, M.-L. Chu, M.-Sh. Shieh, Sep. Sci. Technol. 27, 557 (1992).
[14] P.I. Ndiaye, P. Moulin, L. Dominguez, J.C. Millet, F. Charbit, Desalination 173, 25 (2005).

[15] L. Feenstra, L. Vasak, J. Griffioen, "Fluoride in groundwater, overwiew and evaluation of removal methods", Int. Groundwater Resources Assessment Center, Utrecht, Report no. SP 2007-1.

[16] S. Sourirajan, T. Matsuura, Reverse Osmosis Ultrafiltration Process Principles, National Research Council Canada, Ottawa 1985, p. 79.

[17] Reverse Osmosis and Nanofiltration, 2nd ed., AWWA manual, M46, Denver 2007, p. 10 